\title{
Photovoltaic engineering e-learning applications developed for remote laboratory experimentation systems
}

\author{
Petros J. Axaopoulos • Emmanouil D. Fylladitakis
}

Received: 9 January 2014/ Accepted: 3 March 2014/Published online: 18 March 2014

(c) The Author(s) 2014. This article is published with open access at Springerlink.com

\begin{abstract}
In this paper, a functional remote experimentation system tested for long-term use stability and under real weather conditions is presented. The proposed system offers the ability to students and anyone interested to remotely conduct experiments with a real PV module from anywhere on the planet, as long as an Internet connection is available. This innovative system is based on a $55 \mathrm{~W}_{\mathrm{p}}$ photovoltaic panel installed facing south on the roof of a lab, which is installed on a motorized mount allowing it to alter its tilt angle from $0^{\circ}$ to $90^{\circ}$. A camera offers continuous live video streaming of the test site. In order to demonstrate a portion of the aforementioned system's potential, a set of five proposed educational experiments and exercises that may be performed through the Internet is being comprehensively demonstrated in this paper. Each test creates an $I-V$ and a $P-I$ chart, as well as a TXT file with the test data, which is automatically stored for future use. The procedure only takes a few seconds to complete and the extracted data can then be studied and analyzed in due time, allowing the student to contemplate on the results and put theoretical knowledge into practice. Remote access to a renewable energy lab opens new ways to the education of photovoltaics by offering the students a feeling of direct experience with actual $\mathrm{PV}$ equipment and is a process
\end{abstract}

\section{P. J. Axaopoulos}

Department of Energy Technology, Technological Educational Institute (TEI) of Athens, Ag. Spyridonos, 12210 Aegaleo, Greece

\section{E. D. Fylladitakis $(\square)$}

Electronic and Computer Engineering Department, School of Engineering and Design, Brunel University, Uxbridge, London, UK

e-mail: emmanouil.fylladitakis@brunel.ac.uk exceptionally useful for part-time learners, distance learners, as well as students with disabilities.

Keywords Photovoltaic engineering education - Remote laboratory $\cdot$ PV module $\cdot$ Computer application - Distance education $\cdot$ e-learning

\section{Introduction}

The sun is known to be one of the most important sources of renewable energy, and this energy may be captured almost anywhere on the planet and converted directly into electric power through photovoltaic (PV) panels [1]. Favorable policies, technological advancements and the lowering production costs led to the rapid growth of PV systems over the last decade all around the world. In a few countries the installed PV power multiplied within a single year, as for example in Korea and Spain where it increased six and five times, respectively, from 2007 to 2008 [2].

However, technical specifications provided by PV module manufacturers are always presented at standard test conditions (STC) and are considered insufficient to perform proper modeling [3], with scientists reporting an overestimation of the generation by up to $40 \%$ when performing studies by using the STC figures [4]. Therefore, solar energy engineers need to be capable of extracting the real $V-I$ characteristics of any PV module in order to accurately assess a system's performance and troubleshoot potential problems.

Even though theoretical study is an important aspect of education, in engineering education it is well known that it should be combined with experimentation in order to help the student to become capable of putting the theory into practice [5]. Laboratory experiments are fundamental for 
engineering courses, in order for the students to develop a "feel for engineering" [6]; however, this is not always possible, as access to equipment is limited by a great number of factors, such as the location of the students, the climatic conditions, as well as time and financial constraints. Nevertheless, technology and the Internet can prove to be very valuable tools for current and future engineers, who must today possess a large number of skills and a high level of expertise in order to become successful entrepreneurs [7]. Even though the first Internet-based solar engineering education applications were developed well over a decade ago, technological limitations and the lack of widespread Internet accessibility limited their adoption rates [8]. Still, in advanced countries where today the vast majority of the population has Internet access, Internetbased engineering education is now taking leaping steps forward.

Remote access to laboratories offers many advantages to engineering students and academics alike by allowing access at any time of the day from any part of the world, as long as there is access to the Internet. Some of these advantages are the capability of distance education, the possibility to access laboratories around the globe and take live and/or recorded readings at any time and the opportunity that handicapped students would have to participate in laboratory coursework. Remote laboratory experimentation offers high quality learning experiences in science and engineering education, while adding flexibility, especially in terms of time and special needs [9]. Furthermore, remote laboratories are especially useful when conducting experimental studies with systems that are inaccessible, too large and/or too expensive for physical measurements by students, while they offer similar or greater educational benefits [10].

During the past decade, there have been several papers describing the development of remote access laboratories for specific experiments. Yeung and Huang [11] described the architecture of a system for DC motor controls using a web interface; Restino et al. [12] developed a remotely accessible laboratory setup for the mechanical characterization of materials; Lazar and Carari [13] presented a remotely accessible laboratory for the education of network control systems, and Bellmunt et al. [14] describe the development of a PLC programming course via a remote laboratory system. However, to the best of our knowledge, the development of remote laboratory applications to this date has been limited to indoor sessions only, the equipment of which frequently is easily accessible to everyone attending the course.

The renewable energy laboratory of the Technological Educational Institute (TEI) of Athens has developed simulation software for educational use [15, 16] and today offers remote access to an experimentation module which is installed on the roof of the building. The experimentation module consists of a $55 \mathrm{~W}_{\mathrm{p}} \mathrm{PV}$ panel installed on singleaxis motorized mount, allowing any user to access the web server from the Internet and perform real-time experiments at different tilt angles, extracting the $I-V$ characteristic of the installed panel. Access to the web server of the experimental laboratory module is currently unlimited and it may be accessed through the following website: http:// helioslab.teiath.gr/.

The web server also offers access to a live camera displaying the experimentation setup at any time of the day. This allows the user to determine the exact weather conditions at the site of the experiment, the moment at which he or she will access the web server.

The aim of this paper is the demonstration of the aforementioned experimentation system and remote access server that may be used in engineering education for realtime remote experiments over the Internet, as well as to suggest a number of applications. The following section presents the experimentation setup. Afterwards, five recommended applications are discussed in detail, namely the capability to extract the actual $I-V$ characteristic and its comparison to the one provided by the manufacturer, the determination of the $P-I$ characteristic of the module, the demonstration of cell shading experimentation, the determination of a module's optimal tilt angle and finally the translation of $I-V$ curves. The paper finally includes the results of an assessment that took place by replacing the real-world experiments of undergraduate students with the experiments performed through the remote experimentation system.

\section{Methods}

The laboratory instruments and equipment used to realize the aforementioned remote lab configuration are:

- A Siemens Solar SM55 monocrystalline PV panel.

- An adjustable ohmic load controlled via electronic relays.

- A web server running proprietary software.

- An outdoor web camera allowing the 24/7 live viewing of the rooftop setup.

- Various automation, instrumentation and metering apparatus.

The Siemens Solar SM55 is a monocrystalline silicontype panel rated at $55 \mathrm{~W}_{\mathrm{p}}$, the technical specifications of which may be found in Table 1 . It is installed on a single (vertical) axis tracker facing south, with the tilt angle being adjustable between $0^{\circ}$ and $90^{\circ}$. A pyranometer is installed right above the $\mathrm{PV}$ panel, measuring the total solar irradiance, while a PT100 temperature sensor is attached on 
Table 1 Siemens SM55 PV panel specifications

\begin{tabular}{ll}
\hline$V_{\mathrm{mpp}}$ & $17.4 \mathrm{~V}$ \\
$I_{\mathrm{mpp}}$ & $3.15 \mathrm{~A}$ \\
$V_{\mathrm{oc}}$ & $21.7 \mathrm{~V}$ \\
$I_{\mathrm{sc}}$ & $3.45 \mathrm{~A}$ \\
$R_{\mathrm{s}}$ & $0.359 \mathrm{ohm}$ \\
$\mu_{\mathrm{Voc}}$ & $-0.0736 \mathrm{~V} /{ }^{\circ} \mathrm{C}$ \\
$\mu_{\mathrm{mp}}$ & $-0.0042 /{ }^{\circ} \mathrm{C}$ \\
\hline
\end{tabular}

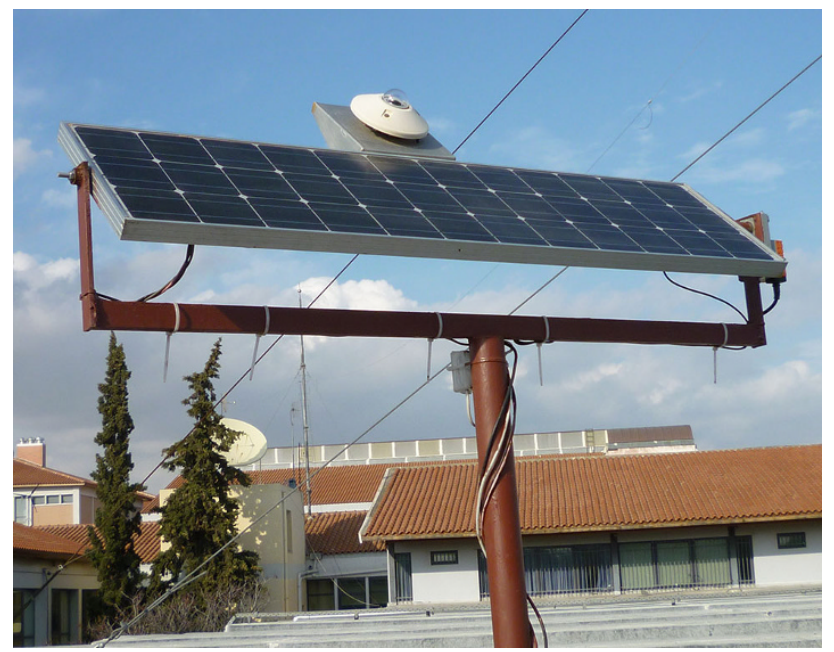

Fig. 1 PV panel, motorized mount and pyranometer configuration on the rooftop of the lab

the back of the PV panel to measure the panel's temperature. The described setup is displayed in Fig. 1 and is located in the TEI of Athens (38.002N, 23.675E).

The automation software automatically determines the optimal panel tilt angle for the solar noon of the day and sets it as the default angle for that day. The software interface allows the user to adjust the tilt angle to any value within the tracker's operational range. The optimal panel tilt angle $\beta_{\text {opt }}$ for each location has been determined by previous research and can be described by the simple mathematical model displayed in Eq. (1) [17].

$\beta_{\text {opt }}=\varphi-\delta$

where $\varphi$ is the latitude of the location and $\delta$ is the declination of the sun, which is given by Eq. (2):

$\delta=23.45 \cdot \sin \left(360 \cdot \frac{284+n}{365}\right)$

where $n$ is the number of the day of the year and ranges between 1 (1st of January) and 365 (31st of December). The system is using these two equations in order to calculate the optimal panel tilt angle at the solar noon of the day every time a test is being requested by a user.

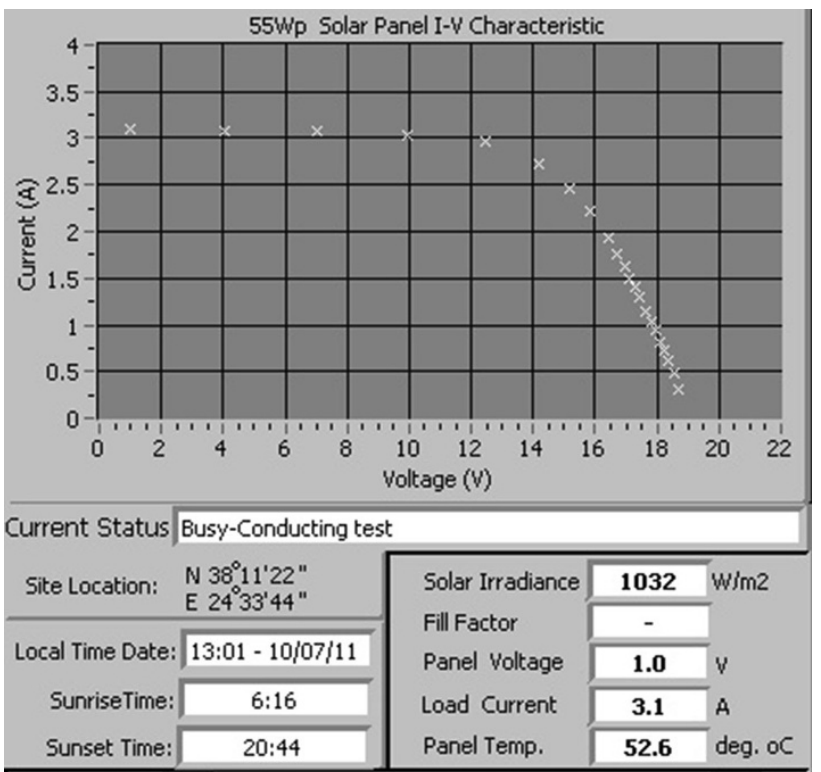

Panel Tilt Angle 17 deg. (0 deg. is horizontal) Today's Optim. Angle 16 deg.

Fig. 2 Indicative $I-V$ curve generated by using the remote experimentation system

The automation and instrumentation devices are connected to the computer hosting the experiment through a twisted pair (UTP) cable in a daisy chain configuration, using the RS485 serial communication protocol. This setup makes it possible to place the various devices at a total distance of 1,200 $\mathrm{m}$ from the computer. In this way, signals generated by the probes can be measured locally, avoiding signal losses due to the attenuation that long cables would cause.

The software is implemented with Labview [18] and has a web interface allowing for remote use, where multiple users can monitor the system concurrently. However, only one test may run at an instance, meaning that if a user requests a test to be performed at a specific angle then the other users will have to wait for this test to be completed before they can request a test at a different angle. Still, each test takes no more than a few seconds and therefore a single panel can still serve a large number of users. If the number of users becomes such that the system has to be accessed very frequently, the installation of more panels can easily alleviate the problem. Once the test is completed, the software extracts the $I-V$ curve of the PV panel, the $P-I$ curve of the PV panel, as well as the following information:

1. The panel voltage.

2. The load's ohmic resistance.

3. The output current.

4. The total solar irradiance on the panel's plane. 


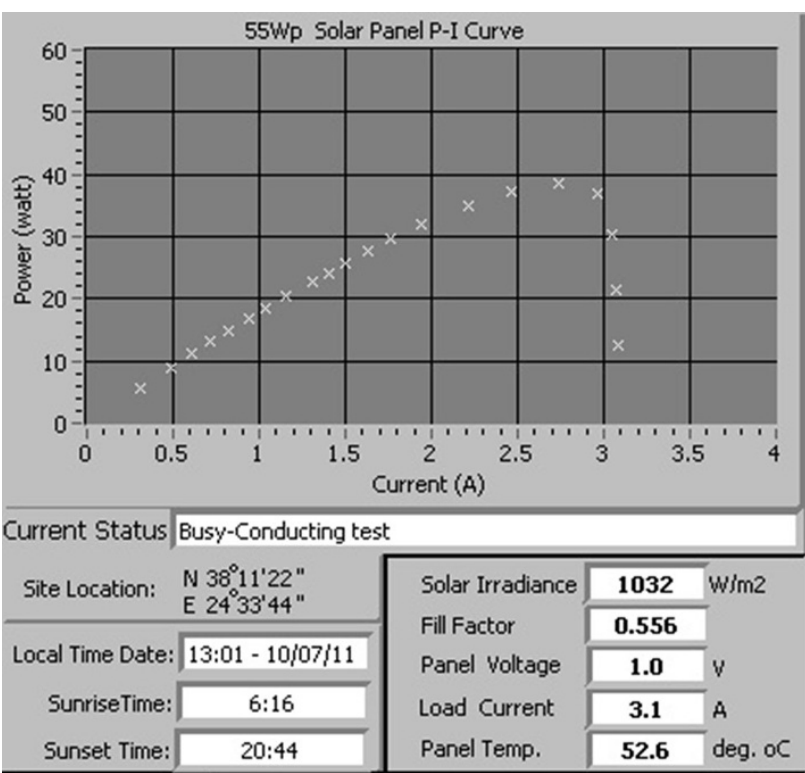

\begin{tabular}{|l} 
Panel Tilt Angle 17 deg. (0 deg. is horizontal) Today's Optim. Angle 16 deg.
\end{tabular}

Fig. 3 Indicative $P-I$ curve generated by using the remote experimentation system

5. The panel's temperature.

6. The test tilt angle and the daily optimal tilt angle.

Figures 2 and 3 display the $I-V$ and $P-I$ curves, respectively, as they were extracted using the remote experimentation setup software from a test conducted on the 10th of July 2011, at 13:01 local time.

The data used to plot Figs. 2 and 3 have been recorded by the system's software at the time of the test and the values can be seen in Table 2. The user may use these data to perform any relevant calculations and/or exercises, as required.

\section{Results and discussion}

In this paper, five recommended applications for educational purposes are being presented. These applications are addressed to both undergraduate and postgraduate engineering students, as well as professionals and individuals who entertain the possibility of experimenting with a real $\mathrm{PV}$ panel fixed on a single-axis tracker and comprehending phenomena that affect the performance of real PV systems. A survey conducted with undergraduate students that used the test system as part of their coursework is also being presented.

\section{Determination of the peak power output}

The objective of this application is for the students to become capable of calculating the real peak power output of a PV panel and comparing it to that of the manufacturer's specifications. This way the students should be able to realize the impact of factors that affect the actual performance of PV panels even under high irradiance levels.

It is known that the manufacturer specifications of PV modules are taken under ideal laboratory conditions and real-world maximum power output is affected by a large number of factors. Some of these factors are debris, water and/or snow, temperature, module mismatching and/or PV module aging [19]. PV aging in particular is an unavoidable and rather severe issue of current PV panels [20]. In the case of our remote laboratory experimental setup, students would need to identify that the performance decline is due to the aged panel, ohmic losses and/or non-ideal climatic conditions (e.g. rain).

The voltage at the maximum power point is known; consequently, the power at maximum power point $\left(P_{\mathrm{mp}}\right)$ is affected by the operating temperature $T_{\mathrm{c}}$ and can be considered to change linearly with the temperature coefficient of the power at maximum power point $\left(\mu_{\mathrm{mp}}\right)$ [21-23].
Table 2 Data acquired by the remote experimentation system software at the time of the presented test

Panel tilted at $17^{\circ}\left(0^{\circ}\right.$ is horizontal)

Panel temperature $\left({ }^{\circ} \mathrm{C}\right)$ during experiment: 52.6

Date: $10 / 07 / 11$; local time: 1:01:50 pm

Site location: $38.002 \mathrm{~N}, 23.675 \mathrm{E}$

\begin{tabular}{lclllrll}
\hline Test count & $V$ (volts) & $I$ (amperes) & $\begin{array}{l}\text { Solar irradiance } \\
\left(\mathrm{w} / \mathrm{m}^{2}\right)\end{array}$ & $\begin{array}{l}\text { Test } \\
\text { count }\end{array}$ & $V$ (volts) & $I$ (amperes) & $\begin{array}{l}\text { Solar } \\
\text { irradiance } \\
\left(\mathrm{w} / \mathrm{m}^{2}\right)\end{array}$ \\
\hline 1 & 18.707 & 0.308 & $1,032.000$ & 12 & 18.217 & 0.717 & $1,032.000$ \\
2 & 17.638 & 1.150 & $1,032.000$ & 13 & 16.947 & 1.625 & $1,032.000$ \\
3 & 18.083 & 0.821 & $1,032.000$ & 14 & 17.816 & 1.038 & $1,032.000$ \\
4 & 15.812 & 2.213 & $1,032.000$ & 15 & 7.015 & 3.067 & $1,032.000$ \\
5 & 17.126 & 1.500 & $1,032.000$ & 16 & 17.304 & 1.400 & $1,032.000$ \\
6 & 9.955 & 3.042 & $1,032.000$ & 17 & 17.950 & 0.942 & $1,032.000$ \\
7 & 17.415 & 1.304 & $1,032.000$ & 18 & 12.427 & 2.967 & $1,032.000$ \\
8 & 14.164 & 2.733 & $1,032.000$ & 19 & 18.529 & 0.483 & $1,032.000$ \\
9 & 16.702 & 1.767 & $1,032.000$ & 20 & 16.435 & 1.942 & $1,032.000$ \\
10 & 4.053 & 3.083 & $1,032.000$ & 21 & 18.373 & 0.608 & $1,032.000$ \\
11 & 15.166 & 2.463 & $1,032.000$ & 22 & 1.002 & 3.096 & $1,032.000$ \\
\hline
\end{tabular}


$P_{\mathrm{mp}}=P_{\mathrm{mp}, \mathrm{r}} \frac{G_{\mathrm{T}}}{G_{\mathrm{T}, \mathrm{r}}}\left[1-\mu_{\mathrm{mp}} *\left(T_{\mathrm{c}}-T_{\mathrm{c}, \mathrm{r}}\right)\right]$

where $P_{\mathrm{mp}, \mathrm{r}}, G_{\mathrm{T}, \mathrm{r}}$ and $T_{\mathrm{c}, \mathrm{r}}$ is power at maximum power point, irradiance and operating temperature at reference conditions respectively and $G_{\mathrm{T}}$ is the irradiance at maximum power point. The reference conditions are defined as: solar irradiance of $1 \mathrm{~kW} / \mathrm{m}^{2}$, cell temperature of $25^{\circ} \mathrm{C}$ and spectral distribution corresponding to an air mass of 1.5 . The parameters regarding the laboratory module are displayed in Table 1.

Despite the large number of equations in literature expressing the dependence of a PV module's electrical power output on temperature [24], Eq. (3) has been acknowledged by many researchers due to its accuracy and good agreement with experimental data [25]. Due to its advantages and especially its simplicity, the above equation is suggested for this educational application.

Students are expected to extract the maximum power output of the PV panel through the proposed educational remote experimentation system and compare it with the theoretical maximum power output of the panel under the same operational conditions, which can be easily calculated from Eq. (3). It is expected that the real power output of the panel will be lower than the one calculated via Eq. (3), the difference of which reveals the impact of aging under clear sky conditions.

Sufficient literature and notes on the factors influencing the performance of PV panels need to be made available to the students for the unproblematic conclusion of this educational application.

\section{Comparison of the $I-V$ curves}

The objective of this application is for the students to become capable of extracting the real $I-V$ curves of a PV panel and compare them to those supplied by the manufacturer.

Although manufacturers provide $I-V$ curves alongside with their panels under different laboratory conditions, it has been proven that they do not represent the performance of the PV panel under real-world conditions [26, 27]. Through this application, students should learn how to extract the real $I-V$ curve of a PV panel under any operational conditions and compare it with the one developed from the manufacturer's specifications. Furthermore, through the aforementioned comparison between the extracted $I-V$ curve with the theoretical $I-V$ curve, the students should learn how other factors can affect the actual performance of a PV panel.

For that purpose, students may use nearly any software developed for PV professionals capable of developing the theoretical $I-V$ curve using the manufacturer's specifications, or transient simulation software.

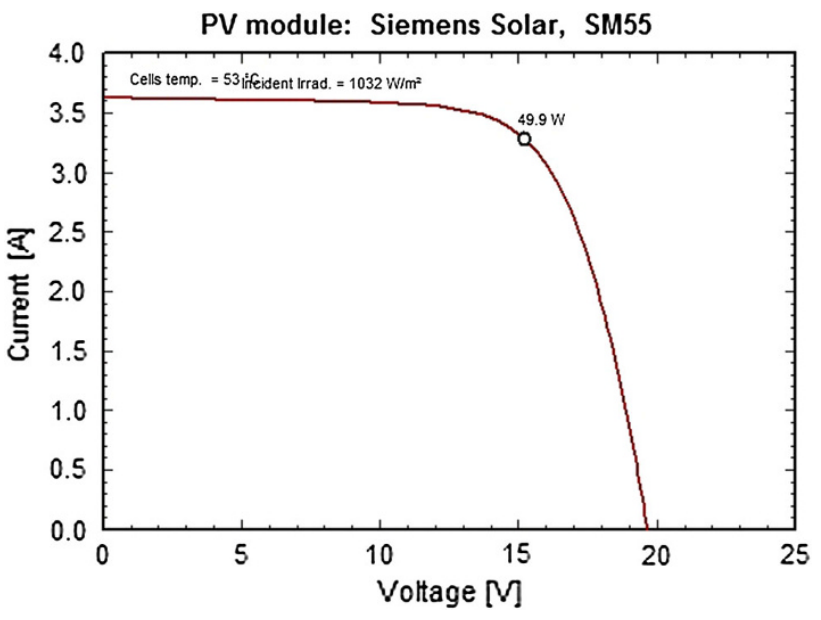

Fig. 4 Theoretical $I-V$ curve of the SM55 panel under specific environmental conditions

Figure 2 displays the real $I-V$ curve of the SM55 panel, as it was extracted from the laboratory setup for a certain date and time. However, Fig. 4 displays the theoretical curve of the Siemens Solar SM55 panel as it was extracted using PVSyst [28] for the exact same environmental conditions.

As the real $I-V$ curve is discernibly lower than the theoretical curve as it was extracted from the software, the student can contemplate over how other factors may affect the actual performance of a PV panel. Some of these factors are:

- Cell aging.

- Environmental temperature and wind.

- Dust and debris.

- Cell mismatching.

- Cable losses.

Once again, sufficient literature on the factors influencing the performance of PV panels should be made available to the students for the unproblematic conclusion of this educational application. Finally, educational licenses of professional PV software should be made available to the students if open-source software is not being made available.

Determination of the maximum power of a shaded PV module

The purpose of this application is for the student to understand the grave effect of shading on the PV power output. The objective is to determine the maximum power of a shaded PV module, as it is being derived from experimental measurement under real weather conditions and then compare it with the theoretical power that the unshaded solar module would deliver. 


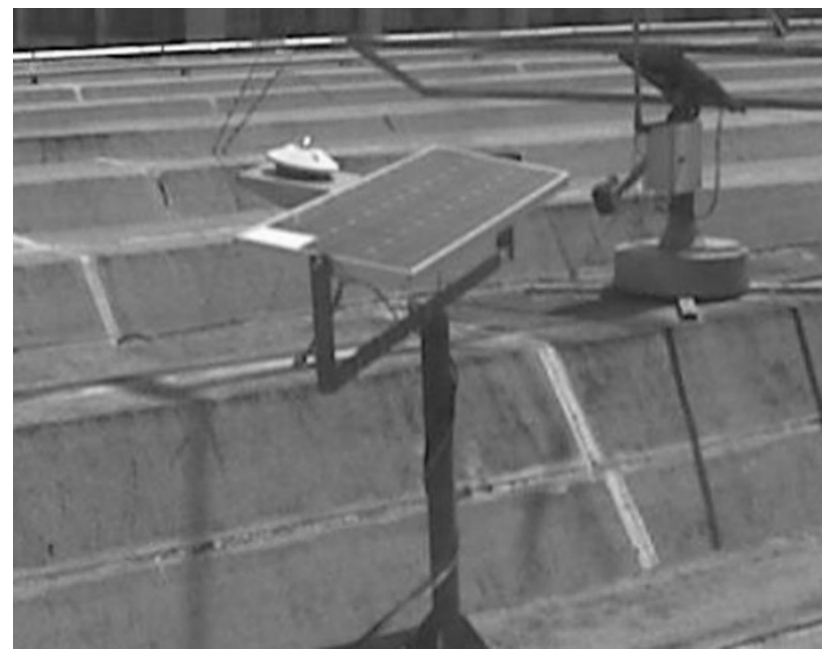

Fig. 5 Picture of the system extracted through its live-view feed system

The shadow effect in PV systems is a very crucial issue, leading not only to the decrease of the power produced but could also impose destructive effects such as cell or glass cracking, melting of solder or degradation of solar cell. This is a common situation due, for example, to the presence of dirt or leaves on one solar cell or shading due to objects such as trees, chimneys, telephone or other utility poles, antennas, bird droppings, architectural features, mechanical equipment or other obstructions that may be found on the roof or any other part of the building and/or its surroundings.

In the case where a cell of a solar module is shaded, the maximum current available from the module is determined by the current of the solar cell that is less illuminated. The shaded cell not only generates less current than the string current of the module, but becomes reverse biased and dissipates power in the form of heat.

A common technique used to eliminate this effect is to employ bypass diodes, which are connected across a block of several cells in a string. In practice, bypass diodes are usually connected by module manufacturers across 16-24 solar cells in order to limit the impact of shading on the solar module. This effect can be easily illustrated by using the proposed remote laboratory.

In order to perform this experiment, students should be informed in advance that the module will be shaded during two specific days of the week and that they should perform the experiment at a time near to the solar noon. The PV module used consists of 36 monocrystalline silicon solar cells with two bypass diodes. One cell of the module is fully shaded with opaque masking tape, as seen in Fig. 5.

When the system is capable of performing a test and a user introduces the desired tilt angle into the appropriate software input box, the system will automatically adjust the tilt of the photovoltaic panel to the desired angle. This

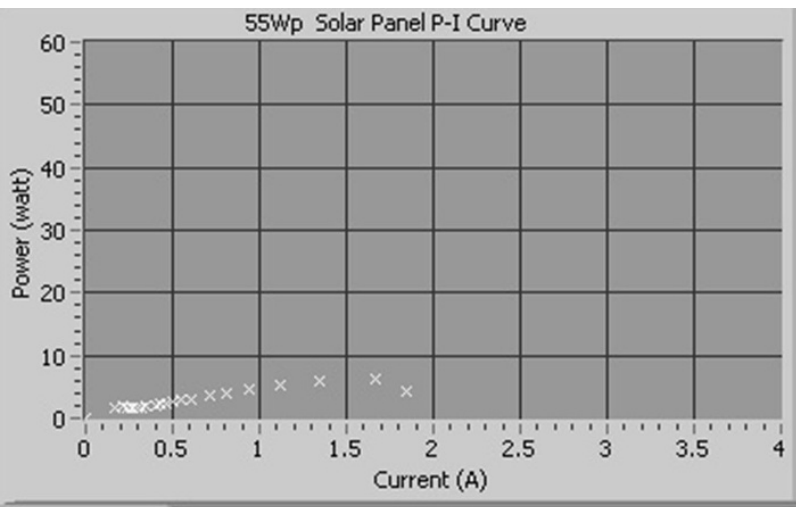

\begin{tabular}{|c|c|c|c|c|}
\hline Current Status & Busy-Conducting t & & & \multirow{3}{*}{ Wim2 } \\
\hline Site Location: & $\begin{array}{l}\text { N } 38^{\circ} 11^{\prime} 22^{\prime \prime} \\
\text { E } 24^{\prime} 33^{\prime} 44^{\prime \prime}\end{array}$ & \multirow{4}{*}{$\begin{array}{c}\text { Solar Irradiance } \\
\text { Fill Factor } \\
\text { V_Panel } \\
\text { I_Load } \\
\text { Panel Temp. }\end{array}$} & \multirow{2}{*}{$\begin{array}{c}616 \\
- \\
7.4\end{array}$} & \\
\hline Local Time Date: & $14: 26-29 / 06 / 12$ & & & \\
\hline SunriseTime: & $6: 10$ & & 0.2 & A \\
\hline Sunset Time: & $20: 50$ & & 50.8 & deg. oC \\
\hline
\end{tabular}

Panel Tilt Angle 15 deg. (0 deg. is horizontal) Today's Optim. Angle 15 deg.

Fig. $6 P-I$ characteristic of the shaded module

procedure can be seen live from the web camera which displays the experimentation setup. After the test is completed, the experimental characteristic $P-I$ curve is displayed on the screen and an external file containing the output data is generated. The user can process the data from the external file and calculate the maximum power for the given operating conditions by using Eq. (3).

For demonstration purposes, the remote laboratory has been used and the obtained $P-I$ characteristic is being displayed in Fig. 6. Due to the educational purpose of this application, the aging of the solar module is ignored since it will not affect the outcome significantly.

Figure 6 displays the real experimental results of the power as a function of voltage of the laboratory module while one of the module's cells is entirely shaded, under a solar irradiance of $616 \mathrm{~W} / \mathrm{m}^{2}$ and operating temperature of $50.8^{\circ} \mathrm{C}$. From this fig, the maximum power can be seen to be $<6.5 \mathrm{~W}$ while, by using Eq. (3) and substituting the appropriate values, the maximum power under identical operating conditions but without shading is $30.1 \mathrm{~W}$.

It should be noted that the power loss is $78 \%$, even though only $2.42 \%$ of the module area is shaded. The massive power loss illustrates the disproportionate reduction of power that could occur from a small shadow covering a single cell.

\section{Determination of the optimal tilt angle}

The purpose of this application is for the student to realize that there is an optimal angle for each day of the year, as 


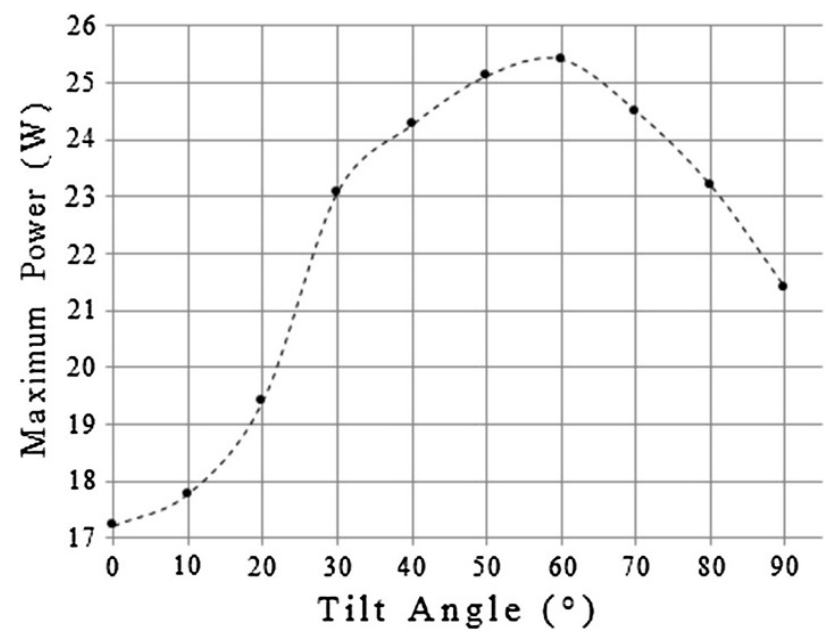

Fig. 7 The maximum power output of the photovoltaic panel at different tilt angles

well as for each hour of the day. The objective of the application is to use the remote experimentation system and take readings for several tilt angles, determining which the optimum tilt angle is for the day and time the test is being conducted.

It is known that the tilt angle of the PV panel largely determines the received solar irradiance and is the primary factor that governs the power output of the panel. As the position of the sun on the celestial sphere changes during the day and follows a different path for each day of the year, it becomes apparent that the determination of an optimal tilt angle is essential for the optimal operation of every PV system [29].

Students are called to determine the optimal tilt angle of the remote laboratory PV panel for a given time and day. By using the software to extract the $P-I$ characteristic curves for several tilt angles between $0^{\circ}$ and $90^{\circ}$, for example in $10^{\circ}$ steps, the students can easily generate a graph displaying the maximum power output of the panel in correlation with the tilt angle, as displayed in Fig. 7. The optimum tilt angle of the example demonstrated in Fig. 7 is high because it is morning (10:34 am), thus the solar altitude is low.

After creating the graph displayed in Fig. 7, it is easy for the student to derive the optimal tilt angle at the location of the PV panel for the specific time and day the test has been conducted. Students can also estimate how much of a performance decrease they can expect as the tilt angle moves away from the optimal.

Translation of the $I-V$ curve

The purpose of this application is for the student to develop the ability to translate the $I-V$ curve of a PV panel to other

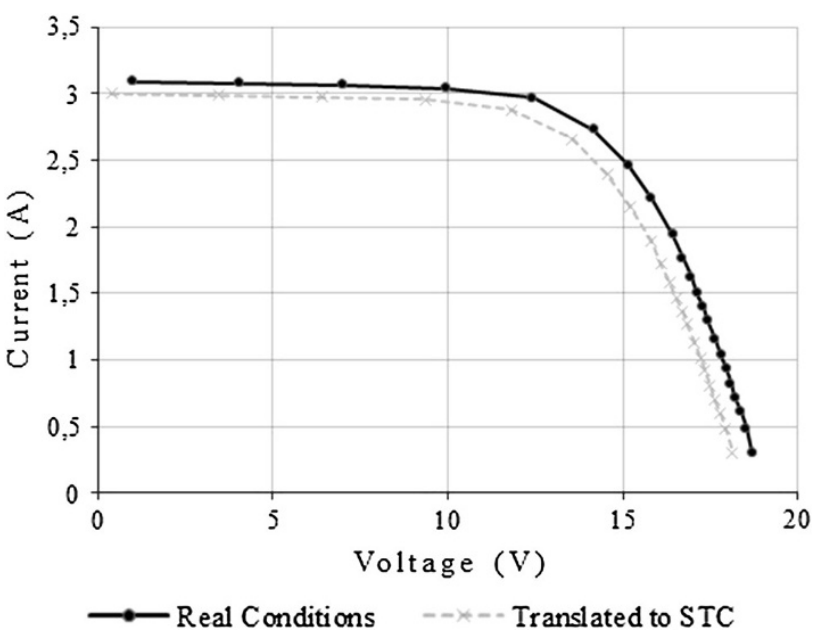

Fig. 8 Real and translated to STC $I-V$ characteristics of the remote laboratory module

environmental conditions. The objective of the application is to use the remote experimentation system to extract an $I-V$ curve under actual environmental conditions and translate it at STC conditions. Academic literature proposes a number of different methods by which the $I-V$ characteristic may be translated [30, 31]. However, the most common method for performance verification is the translation to STC.

The measured current and voltage figures can be translated to the module's STC values by Eqs. (4) and (5) respectively.

$$
\begin{aligned}
I_{\mathrm{STC}}= & I_{\mathrm{r}}\left(\frac{H_{\mathrm{STC}}}{H_{\mathrm{r}}}\right)+a \cdot\left(T_{\mathrm{r}}-T_{\mathrm{STC}}\right) \\
V_{\mathrm{STC}}= & V_{\mathrm{r}}-\beta \cdot\left(T_{\mathrm{STC}}-T_{\mathrm{r}}\right)-R_{\mathrm{S}} \cdot\left(I_{\mathrm{r}}-I_{\mathrm{STC}}\right)+V_{\mathrm{t}} \\
& \cdot \operatorname{LN}\left(\frac{H_{\mathrm{STC}}}{H_{\mathrm{r}}}\right)
\end{aligned}
$$

where $I_{\mathrm{STC}}, V_{\mathrm{STC}}, T_{\mathrm{STC}}$ and $H_{\mathrm{STC}}$ are the current, voltage, temperature and irradiance at STC, respectively; $I_{\mathrm{r}}, V_{\mathrm{r}}, T_{\mathrm{r}}$ and $H_{r}$ are the measured current, voltage, temperature and irradiance, respectively; $\alpha$ is the temperature coefficient of the current, $\beta$ is the temperature coefficient of the voltage, and $R_{\mathrm{S}}$ is the series resistance. $V_{\mathrm{t}}$ is the thermal voltage of the module, which is described by Eq. (6):

$V_{\mathrm{t}}=\frac{(A \cdot k \cdot T)}{q}$

where $A$ is the area of the module, $k$ is the Boltzmann constant, $q$ is the magnitude of the electrical charge of the electron and $T$ is the module's temperature.

Therefore, in this application students are called to translate the real $I-V$ curve extracted from the remote experimentation system to STC conditions, compare it to 
Table 3 Educational assessment of the proposed system

\begin{tabular}{lllll}
\hline $\begin{array}{l}\text { Student's } \\
\text { group }\end{array}$ & $\begin{array}{l}\text { Ex. 1 essay } \\
\text { Average } \\
\text { class mark } \\
(\%)\end{array}$ & $\begin{array}{l}\text { Ex. 1 exam } \\
\text { Average } \\
\text { class mark } \\
(\%)\end{array}$ & $\begin{array}{l}\text { Ex. 2 essay } \\
\text { Average } \\
\text { class mark } \\
(\%)\end{array}$ & $\begin{array}{l}\text { Ex. 2 exam } \\
\text { Average } \\
\text { class mark } \\
(\%)\end{array}$ \\
\hline 1 & 72 & 68 & 67 & 62 \\
2 & 70 & 71 & 64 & 61 \\
3 & 74 & 75 & 70 & 64 \\
4 & 70 & 72 & 69 & 64 \\
5 & 76 & 70 & 72 & 70 \\
6 & 74 & 71 & 70 & 67 \\
\hline
\end{tabular}

the STC provided by the manufacturer of the module and then translate it to the environmental conditions specified by the tutor or depending on the local environmental conditions near the student's residence.

Using the experimental results of the remote lab module depicted in Fig. 2, the new translated $I-V$ characteristic to STC has been calculated using Eqs. (4) and (5). The two curves are presented in Fig. 8.

After the completion of this exercise, students should be capable of translating the $I-V$ curves of any PV panel, as long as a real $I-V$ curve under known environmental conditions has been extracted, to a second $I-V$ curve displaying the performance of a PV panel under STC conditions.

\section{Educational evaluation}

The aforementioned exercises are indicative of the capabilities of the system and may be implemented on any level of an engineering education course, according to the requirements of the curriculum. The system presented in this paper is currently being used by several universities as supplementary educational material for their undergraduate and postgraduate students, as well as by seminar organizers worldwide for the demonstration of a working PV module [32]. An assessment of the functionality, usability and receipt of the remote $\mathrm{PV}$ lab by students has been performed in the TEI of Athens and the results are presented below. It should be noted however that the use of the remote lab is not limited to students, as everyone interested is capable of accessing it, allowing anyone who would like to complete their theoretical knowledge with experimentation experience.

The undergraduate students of the Energy Technology Engineering Department of the TEI of Athens are required to perform laboratory experiments in partial fulfillment of their studies. They are required to perform two of the experiments suggested by this paper: to assess the peak power output of a PV panel and to compare the $I-V$ curve of the panel to that supplied by the manufacturer. Six groups of students are required to perform these experiments per academic year, submit a technical essay based on their experimental findings and take a short written theory exam after each class. Over an academic year, half of the students agreed on using the remote experimentation system presented in this paper rather than visiting the lab in order to perform the experiments. Table 3 depicts the performance of the six groups of this academic year. Groups 1 to 3 visited the lab and groups 4 to 6 performed the experiments using the remote experimentation system. Exercise 1 refers to the assessment of the peak power

Table 4 Questionnaire results

\begin{tabular}{|c|c|c|c|c|c|}
\hline Question & $\begin{array}{l}\text { I disagree } \\
(\%)\end{array}$ & $\begin{array}{l}\text { I partially } \\
\text { disagree }(\%)\end{array}$ & $\begin{array}{l}\text { I neither agree or } \\
\text { disagree }(\%)\end{array}$ & $\begin{array}{l}\text { I partially } \\
\text { agree }(\%)\end{array}$ & $\begin{array}{l}\text { I agree } \\
(\%)\end{array}$ \\
\hline The remote lab was easy to use & 0 & 0 & 0 & 6 & 94 \\
\hline The response time of the remote lab was good & 0 & 4 & 10 & 12 & 74 \\
\hline The data supplied by the remote lab was inadequate & 64 & 20 & 6 & 4 & 6 \\
\hline The remote lab was reliable and access to it trouble-free & 0 & 6 & 14 & 25 & 55 \\
\hline $\begin{array}{l}\text { Using the remote lab to perform the experiments has not been as } \\
\text { rich an experience as visiting the actual lab }\end{array}$ & 84 & 8 & 8 & 0 & 0 \\
\hline $\begin{array}{l}\text { Using the remote lab provided the same "hands-on" experience as } \\
\text { visiting the actual lab }\end{array}$ & 6 & 12 & 10 & 42 & 30 \\
\hline $\begin{array}{l}\text { Using the remote lab has been a more convenient approach rather } \\
\text { than having to visit the actual lab }\end{array}$ & 0 & 4 & 3 & 17 & 76 \\
\hline $\begin{array}{l}\text { If you were to choose again, you would choose visiting the lab over } \\
\text { using the remote lab }\end{array}$ & 84 & 2 & 10 & 0 & 4 \\
\hline $\begin{array}{l}\text { You are overall satisfied with the experience you gained by using } \\
\text { the remote lab }\end{array}$ & 4 & 4 & 6 & 24 & 62 \\
\hline
\end{tabular}


output and exercise 2 refers to the comparison of the $I-V$ curves.

As it can be seen from Table 3, the performance of the students that used the remote experimentation system and did not visit the lab did not decline at all. On the contrary, the data suggest that the performance of the students using the remote experimentation system has increased, yet the improvement is small and can be considered to be within the variance between different classes. Table 4 displays the results of a small questionnaire submitted by the students that chose to use the remote experimentation system over visiting the lab.

It can be easily derived by the results of the questionnaire that the remote experimentation system has been well received by the undergraduate students of the TEI of Athens, even though they had the opportunity to visit an actual lab and perform the experiments themselves. We suspect that students without access to PV lab equipment or located where the climatic conditions prevent the easy performance of live experiments would react even more positively if given access to a remote PV lab.

\section{Conclusions}

It is evident that the developed remote laboratory demonstrated in this paper offers many advantages, to students and academics alike. The greatest advantage of the system lies in its ability to be accessed from any part of the world at any time of the day, as long as there is an available Internet connection, making long distance education on real-world PV systems possible, which is especially useful for distance education and part-time programs. Furthermore, it allows academics and researchers from any part of the world to access the laboratory, extracting real-time and/ or recorded data from the system. Finally, yet importantly, it allows for handicapped students and researchers to access a real-world PV site, making active participation in laboratory coursework and research possible.

As the experimentation system operates under real weather conditions, through the aforementioned experiments, students can move from theory to practice and become capable of calculating the real peak power output of a PV panel by extracting and translating actual $I-V$ curves, comparing them to those supplied by the manufacturer and/or assessing a panel's performance under real environmental conditions. Furthermore, students can research and understand the grave effect shading has on the performance of a PV panel, the effect of the tilt angle and other phenomena, such as aging and temperature, which may affect the longevity and performance of real PV panels and installations.
By allowing remote access from any part of the planet to a renewable energy lab, students and academics from all around the world can perform experiments and then analyze their results in accordance with the known theory, both as a part of a learning program and for self-education purposes. Remote labs are especially useful for colleges and institutions, which offer programs on renewable energy without being able to offer direct access to real-world PV equipment, as well as for distance learning programs and for campuses situated in areas with a low number of sunshine hours. Finally, remote access to experimentation equipment can be especially useful for researchers located all over the planet, since such systems would allow for the extraction of useful data in real time.

Conflict of interest The authors declare that they have no competing interests.

Open Access This article is distributed under the terms of the Creative Commons Attribution License which permits any use, distribution, and reproduction in any medium, provided the original author(s) and the source are credited.

\section{References}

1. Meral, M.E., Dinçer, F.: A review of the factors affecting operation and efficiency of photovoltaic based electricity generation systems. Renew. Sustain. Energy Rev. 15(5), 2176-2184 (2011)

2. International Energy Agency: Photovoltaic power systems programme. Paris (2009)

3. Carrero, C., Rodríguez, J., Ramírez, D., Platero, C.: Simple estimation of PV modules loss resistances for low error modelling. Renew. Energy 35(5), 1103-1108 (2010). doi:10.1016/j. renene.2009.10.025

4. Durisch, W., Tille, D., Wörz, A., Plapp, W.: Characterisation of photovoltaic generators. Appl. Energy 65(1-4), 273-284 (2000). doi:10.1016/s0306-2619(99)00115-4

5. Leach, J., Paulsen, A.: Practical work in science education: recent research studies. Stud. Sci. Educ. 33(1), 168 (1999). doi:10.1080/ 03057269908560146

6. Moore, D.J., Voltmer, D.R.: Curriculum for an engineering renaissance. IEEE Trans. Educ. 46(4), 452-455 (2003). doi:10. 1109/TE.2003.818754

7. Sunthonkanokpong, W.: Future global visions of engineering education. Procedia Eng. 8, 160-164 (2011). doi:10.1016/j. proeng.2011.03.029

8. Cuevas, A., Trevisi, S.: Sunpath, internet-based solar engineering education. Renew. Energy 22(1-3), 99-104 (2001). doi:10.1016/ s0960-1481(00)00020-3

9. Colwell, C., Scanlon, E., Cooper, M.: Using remote laboratories to extend access to science and engineering. Comput. Educ. 38(1-3), 65-76 (2002). doi:10.1016/S0360-1315(01)00077-X

10. Feisel, L.D., Rosa, A.J.: The role of the laboratory in undergraduate engineering education. J. Eng. Educ. 94(1), 121-130 (2005). doi:10.1002/j.2168-9830.2005.tb00833.x

11. Yeung, K., Huang, J.: Development of a remote-access laboratory: a dc motor control experiment. Comput. Ind. 52(3), 305-311 (2003). doi:10.1016/S0166-3615(03)00133-7

12. Restivo, M.T., Mendes, J., Lopes, A.M., Silva, C.M., Chouzal, F.: A remote laboratory in engineering measurement. IEEE Trans. 
Ind. Electron. 56(12), 4836-4843 (2009). doi:10.1109/TIE.2008. 2011479

13. Lazar, C., Carari, S.: A remote-control engineering laboratory. IEEE Trans. Ind. Electron. 55(6), 2368-2375 (2008). doi:10. 1109/TIE.2008.920650

14. Bellmunt, O.G., Miracle, D.M., Arellano, S.G., Sumper, A., Andreu, A.S.: A distance PLC programming course employing a remote laboratory based on a flexible manufacturing cell. IEEE Trans. Educ. 49(2), 278-284 (2006). doi:10.1109/TE.2006. 873982

15. Axaopoulos, P., Pitsilis, G.: Energy software programs for educational use. Renew. Energy 32(6), 1045-1058 (2007). doi:10. 1016/j.renene.2006.08.006

16. Axaopoulos, P., Pitsilis, G., Panagakis, P.: Multimedia education program for an active solar hot water system. Int. J. Sol. Energy 22(2), 83-92 (2002). doi:10.1080/01425910214358

17. Axaopoulos, P.J.: Basic principles of solar geometry. In: PJ Axaopoulos (eds.) Solar thermal conversion. Simmetria, Athens, Greece (2011)

18. Travis, J.: Internet applications in LabVIEW. National Instruments virtual instrumentation series. Prentice Hall, Upper Saddle River (2000)

19. Abdelkader, T.F., Abdulla, A.-H.M., Jamel, B.H.: Study of the effects of dust, relative humidity and temperature on solar PV performance in doha: comparison between mono-crystalline and amorphous PVs. Int. J. Green Energy (2012). doi:10.1080/ 15435075.2012.692134

20. Bhatt, M.S.: Performance evaluation of solar photovoltaic arrays after 18 years of field operation. Int. J. Green Energy (2012). doi:10.1080/15435075.2011.647169

21. Fuentes, M., Nofuentes, G., Aguilera, J., Talavera, D.L., Castro, M.: Application and validation of algebraic methods to predict the behaviour of crystalline silicon PV modules in Mediterranean climates. Sol. Energy 81(11), 1396-1408 (2007). doi:10.1016/j. solener.2006.12.008

22. Osterwald, C.R.: Translation of device performance measurements to reference conditions. Sol. Cells 18(3-4), 269-279 (1986). doi:10.1016/0379-6787(86)90126-2
23. Skoplaki, E., Palyvos, J.A.: On the temperature dependence of photovoltaic module electrical performance: a review of efficiency/power correlations. Sol. Energy 83(5), 614-624 (2009). doi:10.1016/j.solener.2008.10.008

24. Marion, B.: A method for modeling the current-voltage curve of a PV module for outdoor conditions. Prog. Photovolt. Res. Appl. 10(3), 205-214 (2002). doi:10.1002/pip.403

25. Nofuentes, G., Aguilera, J., Santiago, R.L., de la Casa, J., Hontoria, L.: A reference-module-based procedure for outdoor estimation of crystalline silicon PV module peak power. Prog. Photovolt. Res. Appl. 14(1), 77-87 (2006). doi:10.1002/pip.636

26. Zhou, W., Yang, H., Fang, Z.: A novel model for photovoltaic array performance prediction. Appl. Energy 84(12), 1187-1198 (2007). doi:10.1016/j.apenergy.2007.04.006

27. Aranda, E.D., Galan, J.A.G., de Cardona, M.S., Marquez, J.M.A.: Measuring the I-V curve of PV generators. IEEE Ind. Electron. Mag. 3(3), 4-14 (2009). doi:10.1109/mie.2009.933882

28. PVSyst S.A.: PVSyst. University of Geneva. www.pvsyst.com (2014). Accessed 24 Feb 2014

29. Axaopoulos, P.J., Moutsopoulos, K.N., Theodoridis, M.P.: Engineering education using a remote laboratory through the Internet. Eur. J. Eng. Educ. 37(1), 39-48 (2011). doi:10.1080/ 03043797.2011.644764

30. Yuki, T., Yoshihiro, H., Kosuke, K.: Translation equations for temperature and irradiance of the I-V curves of various PV cells and modules. Paper presented at the Conference Record of the 2006 IEEE 4th World Conference on Photovoltaic Energy Conversion, May 2006

31. Sadok, M., Mehdaoui, A.: Outdoor testing of photovoltaic arrays in the Saharan region. Renew. Energy 33(12), 2516-2524 (2008). doi:10.1016/j.renene.2008.02.016

32. KTH (Royal Institute of Technology) \& EXPLORE Energy 2020 HB: Virtual campus multimedia learning material. http://www. exploreenergy.eu/VirtualCampus/Multimedialearningmaterial/ tabid/1005/language/en-GB/Default.aspx (2014). Accessed 24 Feb 2014 